\title{
Long term follow-up of children with chronic hepatitis B: a single center experience
}

\author{
İnci Yaman Bajinn¹, Hülya Demir², İnci Nur Saltık Temizel², Hasan Özen², Aysel Yüce² \\ ${ }^{2}$ Division of Pediatric Gastroenterology, Hepatology and Nutrition and ${ }^{1}$ Department of Pediatrics, Hacettepe University \\ Faculty of Medicine, Ankara, Turkey.E-mail: inciyaman@gmail.com \\ Received: 16th January 2019, Revised: 14th February 2019, Accepted: 18th February 2019
}

SUMMARY: Yaman Bajin İ, Demir H, Saltık Temizel İN, Özen H, Yüce A. Long term follow-up of children with chronic hepatitis B: a single center experience. Turk J Pediatr 2019; 61: 846-851.

Chronic Hepatitis B infection is an important clinical issue because of the associated risk of developing cirrhosis and hepatocellular carcinoma. Especially in children, there is no consensus about the optimal treatment. Clinical features and long-term outcomes of 165 children diagnosed with chronic hepatitis B at our institution between January 1993 and June 2012 were analysed retrospectively. Patients were divided into four groups according to their treatment protocols. The first group received Interferon (IFN) only, the second group started lamivudine (LMV) first then IFN+LMV combined and then continued with LMV only, the third group started with IFN+LMV combined then continued with LMV only and the fourth group received LMV only. After a median follow-up period of 7 years (1-19 years) the highest e-seroconversion (the loss of HBeAg followed by gain of antiHBe antibody) rate, biochemical and virological response was observed with combined (IFN+LMV) treatment regimens. Patients with higher ALT levels were better treatment responders (p: 0.003). Identification of the patients who need to be treated in order to determine the most effective therapy with optimal treatment duration is important to reduce the risk of developing future complications like cirrhosis and hepatocellular carcinoma.

Key words: chronic hepatitis B, treatment, children.

Chronic hepatitis B (CHB) is defined as persistence of hepatitis $B$ surface antigen (HBsAg) for at least 6 months. $^{1}$ It is an important health problem affecting approximately 360 million people around the world. In Turkey, it is estimated that 3.3 million people are chronically infected with hepatitis B virus (HBV). Natural course of the disease is not explicitly explained at present. Some patients live asymptomatically while some others die because of the complications related to HBV. It is presumed that every year approximately 1 million people die because of $\mathrm{HBV}$ related complications around the world. Patients with CHB have a higher risk of developing cirrhosis, end-stage liver failure and hepatocellular carcinoma (HCC) than the normal population (15-40\%). Determining the factors affecting the course of the disease is important in terms of maintaining progress in clinical approach to these patients.

The main drugs for $\mathrm{CHB}$ treatment in children are interferon (IFN) and lamivudine (LMV) however some of the drugs that have been used in adults are approved by United States of America Food and Drug Administration (FDA) for children lately. The effects of the medications on the natural course of the disease cannot be accurately explained. Also, there is no actual consensus about the best method and duration of the treatment. It is also important to determine to which patient group and when the treatment should be applied. The aim of this study was to evaluate the long-term outcome of children with $\mathrm{CHB}$ with and without antiviral treatment. 


\section{Material and Methods}

Patients who were HBsAg positive for at least 6 months were defined as CHB and 165 patients with CHB between January 1993 and June 2012 at Hacettepe University Faculty of Medicine Ihsan Doğramac1 Children's Hospital, Department of Gastroenterology, Hepatology and Nutrition were identified retrospectively.

Age at diagnosis, vaccination history, laboratory findings, follow-up period, route of transmission, liver biopsy results, and treatment responses were analysed according to patient records. Laboratory findings included alanine aminotransferase (ALT), aspartate aminotransferase (AST), gamma glutamyl transferase (GGT), alkaline phosphatase (ALP), total and conjugated bilirubin, albumin, alpha fetoprotein (AFP) and among viral markers HBsAg, AntiHBs, HBeAg, AntiHBe (tested by enzyme-linked immunoabsorbant assay) and HBV DNA (tested by using real time PCR) of all patients assessed at the time of diagnosis and at the end of the follow-up period. For patients under antiviral therapy, ALT, AST, AFP, HBsAg, AntiHBs, HBeAg, AntiHBe and HBV DNA values observed in the 3rd month, 6 th month and 12th month of the treatment were also recorded.

HBeAg-seroconversion (e-seroconversion) was defined as the loss of HBeAg followed by gain of anti-HBe antibody. HBsAg-seroconversion (s-seroconversion) was defined as the loss of HBsAg followed by gain of anti-HBs antibody. Normalization of ALT value was defined as biochemical response; e-seroconversion and HBV DNA decrease under 2,000 IU $/ \mathrm{ml}$ $\left(10^{4}\right.$ copies $\left./ \mathrm{ml}\right)$ was defined as virological response. $^{2}$

The route of the transmission defined as vertical (perinatal) if the mother was HBsAg positive, as horizontal if there was a nonmaternal household known to have HBV infection or history of blood transfusion.

Liver biopsy was offered to patients before treatment and 36 patients agreed to undergo a biopsy. Pathological findings were scored and staged according to the Modified Knodell HAI classification developed by Ishak et al. ${ }^{3}$
Patients with HBV DNA > 20,000 IU/ml $\left(10^{5}\right.$ copies/ml) and ALT $>2 \mathrm{x}$ ULN (upper limit of normal) can start treatment even without a liver biopsy.

European Association for the Study of the Liver Clinical Practice Guidelines recommend that patients without cirrhosis should be considered for treatment when they have HBV DNA levels above $2,000 \mathrm{IU} / \mathrm{ml}\left(10^{4}\right.$ copies/ $\mathrm{ml}$ ), serum ALT levels above the traditional ULN $>40 \mathrm{IU} / \mathrm{L}$ and severity of liver disease assessed traditionally by liver biopsy showing at least moderate necroinflammation and/or at least moderate fibrosis. Antiviral therapy was started in 85 patients according to these criteria.

Treatment is not recommended for patients with mild chronic hepatitis $B$ because of the low efficacy of existing therapies, but these patients should be monitored. Eighty patients, who had mild chronic hepatitis, ALT $<$ ULN and HBV DNA <20,000 IU/ml ( $10^{5}$ copies/ $\mathrm{ml})$, were observed without treatment.

This is a retrospective study including patients diagnosed between 1993 and 2012. Although today there are some other effective antivirals approved by FDA which can be used in certain age groups in children, the main drugs for $\mathrm{CHB}$ treatment in children were interferon (IFN) and lamivudine (LMV) at that time.

Treated patients were divided into 4 groufours according their therapies [IFN $10 \mathrm{MU} /$ $\mathrm{m}^{2}$ thrice weekly and LMV $4 \mathrm{mg} / \mathrm{kg}$ daily (maximum 100mg)]. Group 1: Interferon (IFN) treatment for 6 months (28 patients). Group 2: Lamivudine (LMV) treatment for 3 months and then combined IFN + LMV treatment for 6 months and then continued with only LMV (20 patients). Group 3: Combined IFN+LMV treatment for 6 months and then continued with only LMV (27 patients). Group 4: Only LMV treatment (10 patients). (For treatment groups 2, 3 and 4 LMV was stopped 6 months after e-seroconversion observed.)

E-seroconversion rates were compared between these treatment groups and also between treated and untreated patients. Response to therapy was defined as undetectable $\mathrm{HBV}$ DNA $<2,000 \mathrm{IU} / \mathrm{ml}\left(10^{4}\right.$ copies $\left./ \mathrm{ml}\right)$ in serum, 
e-seroconversion and normalization of ALT.

The effect of these 4 treatment protocols, age at diagnosis, gender and baseline ALT levels on these outcomes were evaluated. $\mathrm{S}$-seroconversion (loss of $\mathrm{HBsAg}$ and gain of anti-HBs) was also checked at every visit.

Statistical analysis: Statistical analyses were performed by using SPSS (Statistical Package for Social Sciences) version 15.0 in the computer. Differences in mean values and the frequency of patients' characteristics between groups were compared using the Mann-Whitney U test and the Fisher's exact test, respectively. All statistical analyses were based on two-sided hypotheses tested with a significance level of $\mathrm{p}<0.05$.

The study protocol was approved by Hacettepe University Faculty of Medicine Medical, Surgical and Drug Researches Ethical Committee via the decision no. HEC 12/87-41 received on 05.06.2012.

\section{Results}

The median age of 165 children with $\mathrm{CHB}$ was 9 years (1-16 years) and median follow-up period was 7 years (1-19 years). One hundred and six patients were $(64.2 \%)$ male and 59 were female (36\%). Route of transmission was vertical for 106 patients (64.2\%). A hundred and eight patients (65.5\%) were born before 1998 when HBV vaccine was not included in the national vaccination programme in our country. When the characteristic findings of the treated and untreated patients were compared; no statistically significant difference was observed (Table I).

The baseline ALT levels (median $82 \mathrm{IU} / \mathrm{L}$, range 41-538 IU/L) and HBV DNA levels (median $558 \times 10^{5}$ copies $/ \mathrm{ml}$, range $76 \times 10^{4}$ to $1,052 \times 10^{5}$ copies $/ \mathrm{ml}$ ) of the treated patients was higher than the baseline ALT (median $33 \mathrm{IU} / \mathrm{L}$, range 11-489 IU/L) and HBV DNA levels (median $4 \times 10^{5}$ copies $/ \mathrm{mL}$, (range $0-452 \times 10^{5}$ copies $/ \mathrm{ml}$ ) of untreated patients and the difference was statistically significant $(\mathrm{p}<0.01)$.

At the end of the follow-up period e-seroconversion was observed in $46(54.1 \%)$ of 85 treated patients vs. $12(15.0 \%)$ of 80 untreated patients, s-seroconversion was observed for $8(9.4 \%)$ of 85 treated patients vs. $0 \%$ of 80 untreated patients. The median age of spontaneous e-seroconversion of untreated patients was found to be 12.5 years (6-18 years).

When untreated patients with and without spontaneous e-seroconversion were compared, despite the fact that it was not found to be statistically significant, initial ALT values (median $61 \mathrm{IU} / \mathrm{L}$, range 23-489 IU/L) the patients with e-seroconversion tended to be higher than the initial ALT values (median $37 \mathrm{IU} / \mathrm{L}$, range 11-289 IU/L) of the patients without spontaneous seroconversion (p: 0.093).

The initial ALT values (median $101 \mathrm{IU} / \mathrm{L}$, range 41-538 IU/L ) of the patients who developed e-seroconversion among treated patients were higher than the initial ALT values (median $65 \mathrm{IU} / \mathrm{L}$, range $41-467 \mathrm{IU} / \mathrm{L}$ ) of the patients without e-seroconversion (p: 0.003).

E-seroconversion rate in all therapy groups was found to be statistically significant (Table II). The highest e-seroconversion rate was observed with treatment Group 2 [LMV/ $(\mathrm{LMV}+\mathrm{IFN}) / \mathrm{LMV}](70 \%)$, followed by Group 1 (IFN) (57\%), then Group 3 [(IFN+LMV)/ LMV] (48\%) and then Group 4 (LMV) (40\%), respectively.

Table I. The Characteristic Findings of Treated and Untreated Patients with Chronic Hepatitis B.

\begin{tabular}{lccc}
\hline Findings & Treated patients (n: 85) & Untreated patients (n: 80) & $\mathrm{p}$ \\
\hline Male/female, n/n & $54 / 31$ & $52 / 28$ & $>0.05$ \\
Age at diagnosis, years* & 9 (1-16 years) & $7(1-16)$ & $>0.05$ \\
Follow-up period, years* & $7(1-19$ years) & $5(1-15)$ & $>0.05$ \\
Vertical transmission, $\mathrm{n}(\%)$ & $47(55 \%)$ & $59(73 \%)$ & $>0.05$ \\
\hline
\end{tabular}

*: median (minimum-maximum) 
Table II. Antiviral Treatment Responses of Treatments Groups.

\begin{tabular}{|c|c|c|c|c|}
\hline \multirow[b]{2}{*}{ Response parameters } & \multicolumn{4}{|c|}{ Treatment Groups } \\
\hline & $\begin{array}{l}\text { Group } 1 \\
\text { IFN } \\
(\mathrm{n}: 28)\end{array}$ & $\begin{array}{c}\text { Group 2 } \\
\mathrm{LMV} /(\mathrm{LMV}+\mathrm{IFN}) / \mathrm{LMV} \\
\text { (n: 20) }\end{array}$ & $\begin{array}{c}\text { Group 3 } \\
(\text { IFN+LMV)/LMV } \\
\text { (n: } 27)\end{array}$ & $\begin{array}{l}\text { Group 4 } \\
\text { LMV } \\
\text { (n: } 10)\end{array}$ \\
\hline $\begin{array}{l}\text { ALT normalization, n (\%) } \\
(\text { ALT <40 IU/L) }\end{array}$ & $18(64.3)$ & $15(75.0)$ & $21(77.8)$ & $5(50.0)$ \\
\hline $\mathrm{P}^{*}$ & $<0.001$ & $<0.001$ & $<0.001$ & $<0.037$ \\
\hline $\begin{array}{l}\text { HBV DNA normalization, n (\%) } \\
(\text { HBV DNA <2000 IU/ml) }\end{array}$ & $14(50.0)$ & $11(55.0)$ & $15(55.6)$ & $4(40.0)$ \\
\hline $\mathrm{P}^{*}$ & $<0.001$ & $<0.001$ & $<0.001$ & $<0.001$ \\
\hline e-seroconversion, n (\%) & $16(57.1)$ & $14(70.0)$ & $13(48.1)$ & $4(40.0)$ \\
\hline $\mathrm{P}^{*}$ & $<0.001$ & $<0.001$ & $<0.001$ & $<0.017$ \\
\hline s-seroconversion, n (\%) & $2(7.1)$ & $3(15.0)$ & $3(11.1)$ & $2(20.0)$ \\
\hline $\mathrm{P}^{*}$ & 0.092 & 0.171 & 0.171 & 0.287 \\
\hline
\end{tabular}

e-seroconversion: loss of HBeAg followed by gain of anti-HBe antibody. s-seroconversion: loss of HBsAg followed by gain of anti-HBs antibody. ALT: alanine aminotransferase; IFN: interferon alpha; LMV: lamivudine;

All patients have HBeAg and HBsAg positivity with HBV DNA levels above 2,000 IU/ml (10 copies/ml) and serum ALT levels above the traditional ULN > 40 IU/L when treatment started.

$\mathrm{P}^{*}$ represents $\mathrm{p}$ values for comparison between before and after treatment.

HBV DNA normalization rate was found to be statistically significant for all treatment groups $(\mathrm{p}<0.001)$, the higher virological response rate was observed in Group 2 and 3. The best biochemical response was observed in Group 3 (Table II).

When the first visit, 3rd month, 6th month, 12th month and final controls of the patients were examined, it was observed that ALT values had started to decrease with the treatment among all of the treatment groups and regressed to the normal limits at the 6th month controls.

Liver biopsy was performed to $36(36 / 165$; $21.8 \%)$ patients. Modified HAI score of 5 patients $(5 / 36$; $13.9 \%)$ were minimal (HAI score range: $1-3), 25$ patients $(25 / 36 ; 69.4 \%)$ were mild (HAI score range: $4-8$ ), 5 patients $(5 / 36 ; 13.9 \%)$ were moderate (HAI score range: $9-12)$ and 1 patient $(1 / 36 ; 2.8 \% 2)$ was severe (HAI score range: 13-18). No statistically significant difference was observed between modified HAI scores in terms of e-seroconversion (p: 0.721). None of our patients developed HCC during the follow-up period.

\section{Discussion}

In childhood, chronic hepatitis $\mathrm{B}$ is an important health problem due to the risk of long-term complications such as liver failure, cirrhosis and HCC. The prevalence around the world is specified as $3.7 \%$ (3.5\% in women and $3.9 \%$ in men). ${ }^{4}$ Although there is no significant difference between women and men, it is a bit more common in men. In our study, male/female ratio was 1.7.

Turkey is one of the middle endemicity regions and HBV prevalence is between 2 to $7 \%$. It is known that the prevalence has decreased after the inclusion of HBV vaccine in routine vaccination programme since 1998. Like our country, in the regions where HBV carriage is observed at a moderate level, most frequent transmission route is vertical transmission. In our study, $64 \%$ of the patients were transmitted vertically. Another reason for that can be that most of our patients were born before 1998 when the HBV vaccine was not included in the national vaccination programme.

The purpose of the treatment for children with $\mathrm{CHB}$ is to prevent cirrhosis, end-stage liver failure, HCC and mortality that may 
develop later in life. Although the virus cannot be completely eradicated with treatment due to the presence of cccDNA in the nucleus of infected hepatocytes, cirrhosis and HCC risk is reduced by the suppression of $\mathrm{HBV}$ replication and associated histological activity. ${ }^{5-8}$ In some studies, it has been shown that patients with female gender, higher ALT levels, lower HBV DNA levels andhigher HAI scores show better response to treatment. ${ }^{9}$ Some of the studies specify that response to the treatment is better when the age decreases. ${ }^{10}$ In our study, ALT values at the time of diagnosis of the patients e-seroconverted with antiviral therapy were found to be higher than the patients not responding to the treatment however age, gender and low HBV DNA and high HAI score were not statistically significant to determine the response to the treatment.

Spontaneous e-seroconversion rate of untreated group increases by age. ${ }^{11}$ Patients infected in perinatal period have a lower seroconversion rate, this ratio increases when the disease is transmitted in the postnatal period. In our study, because most of the patients were infected via vertical route, low seroconversion rate $(15 \%)$ was an expected result.

Spontaneous seroconversion has been shown to occur for most of the patients at the end of adolescence. In a study, it was specified that spontaneous seroconversion of 508 of 773 patients developed before age of 30 years. ${ }^{12}$ In our study, spontaneous seroconversion age was median 12.5 years (6-18 years).

A study observed 52 children with $\mathrm{CHB}$ for median 11 years (3-22 years) and it was shown that e-seroconversion had developed in $87 \%$ of the treated and in $72 \%$ of the untreated patients and HBsAg had not turned out to be negative in any of these patients. ${ }^{13}$ In a study of Iorio et al. ${ }^{14}$, 108 patients were followed for a mean period of 12 years and e-seroconversion rate was $80 \%$ for treated patients and $69 \%$ for the untreated patients and antiHBs turned to positive in $9.7 \%$ of both treated and untreated patients. In our study, when the e-seroconversion ratios were compared, a statistically significant difference was observed between the treated (\%54) and untreated (\%15) group at a median 7 years (119 years $)$ at follow-up period $(\mathrm{p}<0.001)$.
When e-seroconversion ratios were compared among treatment groups, the highest rate was determined in treatment group 2 (LMV/ (IFN+LMV)/LMV) followed by the patients receiving only IFN treatment $(57 \%)$, the lowest ratio was determined in the group receiving only LMV treatment $(40 \%)$. Highest seroconversion rate was obtained by the combined treatment and the lowest rate was observed in the patients receiving only LMV treatment.

Our study showed that biochemical response was achieved among all treatment groups. Virological response was observed in 49 (57\%) of the treated patients. Best biochemical and virological response was observed with combined (IFN+LMV) treatment strategies.

In the literature, both IFN and LMV treatment were found to be efficient in accelerating the e-seroconversion and decreasing the inflammatory activity in $\mathrm{CHB}$ patients. ${ }^{15-22}$ In clinical studies comparing only IFN, only LMV and combined LMV+IFN treatments; it was shown that combined treatment is more efficient than the other treatments in terms of viral suppression. ${ }^{23}$ Sokal et al. ${ }^{24}$ determined that resistance to LMV was developed in $64 \%$ of the patients receiving LMV treatment for 3 years. Thus, only LMV treatment is not preferred. The potential advantages of combined treatment are additive and synergistic antiviral effect, decrease or delay in resistance to virus when compared to the patients receiving only LMV and the disadvantages are higher cost, increase in toxicity and drug interactions. The main expectation from the study is the long-term effect. Our institution previously reported the e-seroconversion rate of patients treated with treatment 2 at 15 months of their treatment as \%55. Our study showed e-seroconversion rate increased to $\% 70$ after median 7 years followup period. ${ }^{25}$

There are no sufficient studies regarding the optimal treatment regimen and duration of the treatment for children with CHB. A multicenter study by Toy et al. ${ }^{26}$ from our country showed monotherapy with agents like entecavir and tenofovir could be efficient and cost effective for children with CHB but our study covered the time period which LMV and IFN was the only treatment options. Our study compared 
the long-term outcome of single IFN, single LMV and 2 different (IFN+LMV) combined treatment regimen.

In order to determine the most efficient treatment approach for children with $\mathrm{CHB}$, more studies sharing their experience about different treatment regimens are needed.

\section{REFERENCES}

1. Lampertico P, Agarwal K, Berg T, et al. EASL 2017 Clinical Practice Guidelines on the management of hepatitis B virus infection. J Hepatol 2017; 67: 370398.

2. Lok AS, Heathcote EJ, Hoofnagle JH. Management of hepatitis B: 2000 summary of a workshop. Gastroenterology 2001; 120: 1828-1853.

3. Ishak K, Baptista A, Bianchi L, et al. Histological grading and staging of chronic hepatitis. J Hepatol 1995; 22: 696-699.

4. Ott JJ, Stevens GA, Groeger J, Wiersma ST. Global epidemiology of hepatitis B virus infection: New estimates of age-specific HBsAg seroprevalence and endemicity. Vaccine 2012; 30: 2212-2219.

5. Raimondo G, Allain JP, Brunetto MR, et al. Statements from the Taormina expert meeting on occult hepatitis B virus infection. J Hepatol 2008; 49: 652-657.

6. Liaw YF, Sung JJ, Chow WC, et al; Cirrhosis Asian Lamivudine Multicentre Study Group. Lamivudine for patients with chronic hepatitis B and advanced liver disease. N Engl J Med 2004; 351: 1521-1531.

7. Brechot C, Thiers V, Kremsdorf D, Nalpas B, Pol $S$, Paterlini-Bréchot P. Persistent hepatitis B virus infection in subjects without hepatitis B surface antigen: Clinically significant or purely "occult"? Hepatology 2001; 34: 194-203.

8. Brechot C. Pathogenesis of hepatitis B virus-related hepatocellular carcinoma: Old and new paradigms. Gastroenterology 2004; 127(5 Suppl 1): S56-S61.

9. Huo T, Wu JC, Hwang SJ, et al. Factors predictive of liver cirrhosis in patients with chronic hepatitis B: a multivariate analysis in a longitudinal study. Eur J Gastroenterol Hepatol 2000; 12: 687-693.

10. Wong GL, Wong VW, Choi PC, et al. Evaluation of alanine transaminase and hepatitis B virus DNA to predict liver cirrhosis in hepatitis $B$ e antigen-negative chronic hepatitis B using transient elastography. Am J Gastroenterol 2008; 103: 3071-3081.

11. Fattovich G, Bortolotti F Donato F. Natural history of chronic hepatitis B: special emphasis on disease progression and prognostic factors. J Hepatol 2008; 48: 335-352.
12. Chen YC, Chu CM, Liaw YF. Age-specific prognosis following spontaneous hepatitis $\mathrm{B}$ e antigen seroconversion in chronic hepatitis B. Hepatology 2010; 51: 435-444.

13. Fujisawa $\mathrm{T}$, Komatsu $\mathrm{H}$, Inui $\mathrm{A}$, et al. Long-term outcome of chronic hepatitis B in adolescents or young adults in follow-up from childhood. J Pediatr Gastroenterol Nutr 2000; 30: 201-206.

14. Iorio R, Giannattasio A, Cirillo F, D'Alessandro L, Vegnente A. Long-term outcome in children with chronic hepatitis B: a 24-year observation period. Clin Infect Dis 2007; 45: 943-949.

15. Vo Thi Diem H, Bourgois A, Bontems $\mathrm{P}$, et al. Chronic hepatitis B infection: long term comparison of children receiving interferon alpha and untreated controls. J Pediatr Gastroenterol Nutr 2005; 40: 141145 .

16. Sokal E. Drug treatment of pediatric chronic hepatitis B. Paediatr Drugs 2002; 4: 361-369.

17. Sokal E. Lamivudine for the treatment of chronic hepatitis B. Expert Opin Pharmacother 2002; 3: 329339.

18. Lok AS. Hepatitis B infection: Pathogenesis and management. J Hepatol 2000; 32 (1 Suppl): 89-97.

19. Sokal EM, Conjeevaram HS, Roberts EA, et al Interferon alfa therapy for chronic hepatitis B in children: a multinational randomized controlled trial. Gastroenterology 1998; 114: 988-995.

20. Lau DT, Khokhar MF, Doo E, et al. Long-term therapy of chronic hepatitis B with lamivudine. Hepatology 2000; 32 (4 Pt 1): 828-834.

21. Hoofnagle $\mathrm{JH}$, di Bisceglie AM. The treatment of chronic viral hepatitis. N Engl J Med 1997; 336: 347 356.

22. Saltik-Temizel IN, Kocak N, Demir H. Interferonalpha and lamivudine combination therapy of children with chronic hepatitis B infection who were interferon-alpha nonresponders. Pediatr Infect Dis J 2004; 23: 466-468.

23. Gurakan F, Kocak N, Ozen H, Saltik-Temizel IN, Yuce A. Lamivudine versus LMV+IFN alpha as initial therapy for children with choronic hepatitis B (First year results). J Hepatol 2001; 34: 176.

24. Sokal EM, Kelly DA, Mizerski J, et al. Long-term lamivudine therapy for children with $\mathrm{HBeAg}$-positive chronic hepatitis B. Hepatology 2006; 43: 225-232.

25. Saltik-Temizel IN, Koçak N, Demir H. Lamivudine and high-dose interferon-alpha combination therapy for naive children with chronic hepatitis B infection. J Clin Gastroenterol 2005; 39: 68-70.

26. Toy $\mathrm{M}$, Onder FO, Idilman $\mathrm{R}$, et al. The costeffectiveness of treating chronic hepatitis B patients in a median endemic and middle income country. Eur J Health Econ 2012; 13: 663-676. 